Article

\title{
Exploring the Relationship between Law Students' Prior Performance and Academic Achievement at University
}

\author{
Katri Kleemola ${ }^{1, *(1)}$ and Heidi Hyytinen ${ }^{2}$ \\ 1 Teaching and Learning Services, University of Helsinki, 00100 Helsinki, Finland \\ 2 Centre for University Teaching and Learning, Faculty of Educational Sciences, University of Helsinki, 00100 \\ Helsinki, Finland; heidi.m.hyytinen@helsinki.fi \\ * Correspondence: katri.kleemola@helsinki.fi
}

Received: 23 August 2019; Accepted: 7 September 2019; Published: 11 September 2019

check for updates

\begin{abstract}
As Finnish university admissions are reformed, more information is needed on the relationship between performance in prior education and later academic achievement. Transition to university is a critical period, and low performance in prior education is associated with challenges in later study. In the present study, law students' $(n=426)$ performance in the National Matriculation Examination was investigated in relation to later academic achievement at university. Quantitative methods were used. Findings showed that prior performance was not only associated with study success but also with study progress. The results also showed that law students who had grades in the advanced mathematics course were faster and more successful at university. This work contributes to the existing knowledge of university admissions ahead of the Finnish reform by providing new insights into prior performance and how it is related to academic achievement at university.
\end{abstract}

Keywords: higher education; transition to university; academic achievement; law students; performance in prior education

\section{Introduction}

The highly selective Finnish university admissions systems are currently based on entrance examinations, which mainly test whether an applicant possesses sufficient discipline-specific content knowledge and skills to undertake university studies. At present, there is little emphasis on prior performance, like the National Matriculation Examination, which is based on the curriculum of the Finnish upper secondary school. However, university admissions are being reformed and there are plans to increase the weight of the Matriculation Examination in admission to all Finnish universities. In 2020, half of the students will be admitted according to their Matriculation Examination grades [1].

In order to provide universities with tools to support beginning students' academic achievement, i.e., study progress and study success, we need more information on university admissions, students' prior performance, and their connection to academic achievement. The present study focuses on students in the competitive law programme. We explore the topic by utilising registry data that include university study records and grades from the Matriculation Examination. This study examines how prior performance in the Matriculation Examination is related to students' later academic achievement in the law programme after the first three study years. Studies concerning student admissions have been scarce in the Finnish higher education context. Thus, the present study is expected to not only give new insights into academic achievement, but also to provide new information for developing Finnish university admissions and to identify future research directions. 


\subsection{Transition to Higher Education}

Transition from upper secondary school to university is a critical period for students' forthcoming academic success [2,3]. Previous research has shown that first year students have the highest risk of dropping out [4]. The reasons behind this are not only academic, but because of unclear goals (i.e., students do not really know why they are attending university) or environmental and cultural mismatches with studying at a university and studying at an upper secondary school [2-5]. Thus, it is not a surprise that this topic has been an international research interest for a long time.

While transitions to higher education can be studied from a range of perspectives, the major interest has been on explaining why the transitions succeed or fail [6], and how students' first year experiences influence their study paths during their time at university and the quality of their learning outcomes [2,4]. It has been suggested that students' challenges in learning during the first study year do not only affect the quality of learning outcomes, but may also cause significant delays in study progress and even lead to students dropping out [2-4]. Previous research has also found that students' academic background plays a significant role in their learning outcomes [7]. First-year students who start their studies with a good foundation for learning and are academically engaged are more likely to complete their studies than their peers without these attributes [2,4]. Students with relatively low achievement during upper secondary school seem to have more difficulty in adjusting to university [4]. Recent longitudinal research has found that law students with problems in the first study year, especially in terms of the progress of studies, have delayed graduation [3].

\subsection{What is Academic Achievement?}

There is no agreement on a definition for what constitutes academic achievement [8]. Traditionally, in international research on higher education, university grade point average (GPA) has been used as the measure of academic achievement [9]. However, grades have found to be an unreliable measure of learning outcomes, due to problems in the alignment of assessment [10]. This raises a question about whether GPA alone should be used as a measure of academic achievement. Another way to measure academic achievement is study progress, i.e., how many study credits a student gains during a period or how many exams a student passes [11,12]. In a recent study, study progress was used as the measure of academic achievement on the assumption that for a student, finishing a course is a more important goal than a grade [12]. However, it has recently been shown that a wide variety of individual and contextual factors, e.g., lack of self-regulatory skills, requirements of the degree programme, and one's family life, influence study progress during university studies [13]. Thus, the effects of a single factor can be small. Furthermore, while GPA, study credits, and passed exams are clear-cut measures, academic achievement can be defined in many ways, depending on the perspective used, whether it is the students', teachers', or universities' viewpoint. For example, from the viewpoint of students, qualifications and graduation can be important. However, at the same time, a university's priorities can be defined by the factors that are crucial for its financing [12], such as the number of degrees awarded, the number of students, or the quality of research outcomes. In addition, teachers may emphasise a variety of cognitive and non-cognitive factors as a measure for academic achievement, such as critical analysis skills, ethical values, personal growth, and more [8]. In the Finnish higher education context, both a grade and number of study credits (ECTS) are registered for each course, and earlier in the Finnish higher education research, it was concluded that both measures are relevant components of academic achievement $[3,14]$. Therefore, in the present study, we focus on study progress (study credits) and study success (GPA) as measures of academic achievement at university, utilising registry data. We assume that using both measures can give us an overall picture of students' academic achievement.

\subsection{Prior Grades as a Predictor of Later Academic Achievement at University}

Traditionally, various prior performance measures have also been used as predictors of academic achievement at university. For instance, the secondary school or high school GPA, SAT scores 
(USA), and A level points (GB) have been used as predictors [9]. In Finland, students complete the National Matriculation Examination at the end of the upper secondary school. The purpose of the Matriculation Examination is to determine whether students have acquired the knowledge and skills required by the curriculum for upper secondary school. For a more detailed description of the Matriculation Examination, see the Context of the Study section. In addition, universities arrange entrance examinations to select their students. However, in the Finnish educational context, there is no strong testing or comparison culture. Thus, it is not surprising that the National Matriculation Examination and entrance examination performance have rarely been used as predictors of academic achievement [14-16].

A recent meta-analysis found that the strongest predictors of university GPA are motivational factors of performance self-efficacy and self-assigned grade goals and the prior performance variables of high school GPA and standardised college test ACT [9]. The relationship between prior performance and academic achievement at university has also been studied on other levels. For instance, significant relationships have been found between secondary school performance and the grades in an individual university course [17]. In addition, secondary school grades were found to be related to the number of exams passed at university [11]. It has been suggested that the predictive power of the secondary school GPA is due to the diversity of subjects and assessing teachers associated with the GPA measure [18]. However, the predictive power of individual subjects has also been investigated. In a study on science students' achievement, secondary school mathematics grade was found to be the most significant predictor of the study credits [12]. Previous research has shown contradictory associations between the Finnish Matriculation Examination performance and study progress and study success. The Matriculation Examination grades predict medical students' grades in basic and advanced studies but not their study progress [14,15]. On the contrary, the Matriculation Examination grades of students in social sciences and humanities did not predict study success [16]. The contradiction could be explained by disciplinary differences in the predictive power of the Matriculation Examination performance, which a recent report has suggested to exist in the Finnish higher education context $[19,20]$. These contradictory results thus call for a more thorough examination of the relationship between performance in the Matriculation Examination and later academic achievement.

Overall, trying to predict academic achievement at university based on one factor is problematic. First year studies require quite different skills from the later years at university [21] and different phases may have different predictors [15]. Some findings show that while secondary school performance predicts later academic achievement at university, the predictive power decreases as studies advance [22]. In the present study, we address this issue by including study records from the first three years of university study and including variables for both study progress and study success. As educational systems differ between countries, international research cannot necessarily be generalised in the Finnish context. However, as the Matriculation Examination is to receive increased weight in future university admissions [1], there is a need for a study that focuses on the Matriculation Examination performance in relation to academic achievement at university.

\subsection{Aim of the Study}

In the present study, we investigate one of the more popular disciplines in Finnish higher education. In particular, we explore law students' academic achievement, utilising registry data. We are interested in finding out whether academic achievement at university, i.e., study progress and study success, can be associated with a student's performance in prior education. Students' prior performance is explored by students' performance in the Matriculation Examination. In addition, the present study is expected to provide new important information for the development of university admissions in Finland.

Our research questions are as follows:

1. How are prior performance in the Matriculation Examination and later academic achievement in university related to each other for law students? 
2. What groups can be detected within law students based on their Matriculation Examination performance?

3. What differences in academic achievement can be found between the groups?

Based on earlier research in the Finnish higher education context, it seems that a significant positive relationship should be found between students prior performance and study success, but not study progress [14]. However, because recent reports have suggested disciplinary differences [19], our findings on law students might be different from the earlier findings on medical students $[14,15]$.

\section{Materials and Methods}

\subsection{Context of the Study}

The study was conducted at a large research-intensive university in Finland. Students are admitted according to discipline-specific entrance examinations and National Matriculation Examination grades. University studies are funded by the state, and according to the Bologna regulations, the estimated time for completing is five years.

\subsubsection{The Finnish National Matriculation Examination}

By the end of upper secondary school, Finnish students take the National Matriculation Examination. While the Matriculation Examination is a national examination, students can choose from a large selection of subjects. The Matriculation Examination includes a minimum of four tests, but most students take additional tests. The only compulsory test is for Finnish (the test for Native Language can also be Swedish or Sami, but in the present study all students were Finnish-speaking). In addition, students can choose from mathematics (advanced or basic course), Swedish, the second national language (advanced or intermediate course), foreign languages (advanced or basic course), humanities, and natural sciences. Foreign languages include a variety of languages, the advanced course in English being the most popular amongst them. Humanities and natural sciences include 11 subjects to choose from: biology, chemistry, ethics, geography, health education, history, philosophy, physics, psychology, religion, and social studies. Tests are graded on a six-point scale. The assessment system is such that grades are comparable between examination periods. Only individual tests are graded, no general grades have been awarded since 1996.

\subsubsection{University Admissions in Finland}

In Finnish university admissions, universities have traditionally had freedom to admit their students according to their preferred means. Entrance examinations have been emphasised in most disciplines. Entrance examinations test knowledge in discipline-specific content. The Matriculation Examination grades have been given less weight in most disciplines. Most commonly, half of the students are admitted according to their entrance examinations scores alone. The rest are granted additional scores for four or five of their Matriculation Examination grades on top of their entrance examination scores. Finnish university admissions are highly selective. Approximately $27 \%$ of the applicants are admitted, but in some disciplines, less than 3\% are admitted [23]. Due to the selectivity, university students are a more homogenous group in their prior academic performance than in countries with less-selective admissions.

In future, the Matriculation Examination will have more weight in the admissions, and half of the students will be admitted based only on their Matriculation Examination grades [1]. Scoring tables for Matriculation Examination grades have been created (see example in Appendix A), weighting individual subjects by their respective workload in the upper secondary school curriculum. Furthermore, degree programmes can set a threshold, requiring applicants to have a grade in a subject relevant to their studies. For instance, a student applying to a biology programme would need a grade in biology. In the law programme, no threshold has been set so far. The present study provides information about the 
need for a threshold in the law programme. The methods used in the present study were exploratory, utilising different elements of the planned admissions tool, namely, the scoring table and the threshold.

\subsubsection{Students in the Faculty of Law}

Each year, approximately $10 \%$ of applicants are admitted to the faculty and 250 new law students begin their studies at the university. The target duration of law studies is five years: three years for the bachelor's degree (180 ECTS) and an additional two years for the master's degree (120 ECTS). The bachelor's degree has limited relevance for the labour market, and thus, the goal of nearly all students is to graduate with a master's degree. The majority of Finnish law students $(90 \%)$ graduate as Masters of Law and their dropout rate is among the lowest of all degree programmes [24].

In the Faculty of Law admissions in 2013 and 2014, there were two quotas for students. Half of the law students were admitted according to a so-called total score: the sum of their entrance examination scores and scores based on their Matriculation Examination grades. Matriculation Examination grades form approximately a third of the total score. Furthermore, the other $50 \%$ of the students were admitted based on their entrance examination score alone.

\subsection{Participants and Data Collection}

The data for the present study were collected as part of the National Project for Student Admissions Reform. Overall data included all first-year students in three disciplines enrolled in at beginning of academic years 2013 and 2014 ( $N=702$ ). In the present study, we focused on Finnish-speaking students in the Faculty of Law $(\mathrm{n}=441)$. Thirteen students with no Matriculation Examination grades in the records were excluded. While these students were individuals with a background in a vocational school or in an international upper secondary school, detailed information about their backgrounds was not available. Furthermore, two students who dropped out were removed. The final analysis data for the present study included 426 law students. The mean age of the participants was 21.90 years ( $\mathrm{SD}=3.40 ; \mathrm{min} / \mathrm{max} 18 / 42$ years) when they first enrolled. Of the participants, $290(68 \%)$ were female and $136(32 \%)$ were male.

The data were collected at two time points. First, the data for the Matriculation Examination grades were collected when the student applied for entry to university. Second, the data for students' university grades and study credits (ECTS) were collected three years after the student first enrolled. The data were obtained from the university administration.

\subsection{Measures}

\subsubsection{Academic Achievement}

Academic achievement was considered a two-dimensional construct, and both study progress and study success were measured. Study progress was measured by the number of study credits (ECTS) per academic year during the first three years. First, the sum of the study credits for three years was calculated. Second, students with a year of absence were considered. They were compared with students without absences in their Matriculation Examination grades and academic achievement at university during the years of presence. As no significant differences were found, students with a year of absence were included in the data. To include them, average credits per academic year were calculated. For the students with no absences, the sum of study credits was divided by three. For the students with a year of absence, sum of credits was divided by two. Study success was measured by a student's GPA during the first three years. GPA was based on the grades obtained in the courses students took. Most courses were graded on a numeric five-point scale, 5 being the highest grade and 1 the lowest grade. Some courses were graded on a pass/fail basis. In calculating the GPA, courses with a pass/fail grading were excluded. Most of the introductory courses in the law studies were graded on a pass/fail basis, which provided challenges in investigating study success. It follows that 
no longitudinal research on the development of grades during the first study years could be conducted. Therefore, in the present study, a cumulative GPA of the first three years was used.

\subsubsection{Prior Performance}

Prior performance was measured by the Matriculation Examination test grades and subject choices. The Matriculation Examination tests are graded on a six-point scale using Latin phrases, laudatur being the highest grade and approbatur being the lowest grade. For the purposes of statistical analysis, grades were recoded into numeric grades. The highest grade (laudatur) was recoded as 6 and the lowest grade (approbatur) was recoded as 1.

There were 31 subjects in the present data, but in some of them, only one or two students had a grade. In order to maintain reasonable group sizes in statistical analyses, subjects for which at least $15 \%$ of students had a grade were selected for further analysis. These selected subjects were English (advanced course), Finnish, history, mathematics (advanced course), mathematics (basic course), psychology, social studies, Swedish (advanced course), and Swedish (intermediate course).

In order to be able to assess the overall performance in the Matriculation Examination, a Diploma Score for each student was calculated. The Diploma Score was calculated from the scoring table that the Faculty of Law plans to use in their admission procedures in the future. The Diploma Score was based on five Matriculation Examination grades, as follows: Finnish, and four other subjects that bring the student the best score in the scoring table (see the scoring table in Appendix A). As an alternative way to assess overall performance, each student's average grade in the Matriculation Examination tests was used. The findings were in line with the analyses in which the Diploma Score was used. We chose to report our findings on the Diploma Score as it is of interest from the viewpoint of the ongoing reform in Finnish university admissions.

\subsection{Analyses}

All analyses were conducted using SPSS 24 software. To find out how prior performance in the Matriculation Examination and later academic achievement at university are related to each other, we conducted a Pearson correlation analysis. In addition to the academic achievement variables (study progress and study success), grades for the selected subjects and the Diploma Score were included in the analysis.

As it has been suggested that different analysis methods should be utilised in order to avoid overrunning variation in the data $[25,26]$, our next phase of analysis was to investigate what groups, if any, could be detected within the law students based on their Matriculation Examination performance. First, students' subject choices in the Matriculation Examination were analysed. We identified students with any grade and students with no grade in the selected subjects, simulating an admission threshold. In addition, students' course choices (advanced, intermediate, or basic course) were considered when applicable. Second, students were divided into groups according to their overall performance in the Matriculation Examination using the Diploma Score, simulating usage of the scoring table. Students were categorized in low-, mid-, and high-performance groups using standard deviation, so that cut points were half a standard deviation below the mean and half a standard deviation above the mean.

Finally, in order to discover what differences can be found between the detected groups in terms of academic achievement at university, we conducted a series of MANOVAs. We compared the groups in students' academic achievement (study progress and study success). Furthermore, univariate post hoc tests (Tukey or Dunnett's T3) were conducted if the MANOVA showed significant differences. In addition, gender effects were investigated but no significant differences between genders were found. 


\section{Results}

\subsection{Students' Prior Performance in the Matriculation Examination, Academic Achievement and} Their Relationship

The Pearson correlation analysis showed that law students' Diploma Score and grades in all of the selected subjects had significant positive correlations with study success, with the exception of the basic course in mathematics. Furthermore, the Diploma Score and the grades in history, the advanced course of mathematics, and the intermediate course of Swedish had significant positive correlations with study progress (see Table 1). Effect sizes in all detected correlations were small or medium at best.

Table 1. Correlations between Matriculation Examination grades and academic achievement in university. Correlations that are significant at the 0.01 level are bolded and correlations that are significant on the 0.05 level are italicized.

\begin{tabular}{cccc}
\hline & $\mathbf{n}$ & Study Progress & Study Success \\
\hline Study progress & 426 & - & $\mathbf{0 . 4 2}$ \\
Study success & 426 & $\mathbf{0 . 4 2}$ & - \\
Diploma Score & 426 & $\mathbf{0 . 2 4}$ & $\mathbf{0 . 3 8}$ \\
English (advanced course) & 418 & 0.05 & $\mathbf{0 . 2 5}$ \\
Finnish & 426 & 0.06 & $\mathbf{0 . 2 4}$ \\
History & 162 & $\mathbf{0 . 2 2}$ & $\mathbf{0 . 2 8}$ \\
Mathematics (advanced course) & 206 & $\mathbf{0 . 2 1}$ & $\mathbf{0 . 3 4}$ \\
Mathematics (basic course) & 126 & 0.08 & 0.16 \\
Psychology & 79 & 0.13 & 0.27 \\
Social Studies & 248 & 0.12 & $\mathbf{0 . 3 0}$ \\
Swedish (advanced course) & 81 & 0.14 & $\mathbf{0 . 3 3}$ \\
Swedish (intermediate course) & 294 & $\mathbf{0 . 2 5}$ & $\mathbf{0 . 3 6}$ \\
\hline
\end{tabular}

\subsection{Groups within the Law Students Based on Their Matriculation Examination Performance}

As noted above, students were divided into groups according to two methods. First, we analysed students' subject choices in the Matriculation Examination and variation was found in most of the selected subjects (see Table 2). Thus, we formed groups based on subject choices. Regarding history, psychology, and social studies, students could be divided into two groups: students with any grade and students with no grade in the respective subject. In mathematics, students could be divided into three groups: students with any grade in the advanced course of mathematics, students with any grade in the basic course of Mathematics, and students with no grade in mathematics. In Swedish, students could be divided into three groups: students with any grade in the advanced course of Swedish, students with any grade in the intermediate course of Swedish, and students with no grade in Swedish. Regarding English, no groups were formed, as only eight of the 426 students had no grade in the advance course. Also, regarding Finnish, no groups were formed, as all 426 students had a grade, Finnish being a compulsory test in the Matriculation Examination.

Table 2. Students' subject choices (n).

\begin{tabular}{ccccc}
\hline Subject & No Grade & $\begin{array}{c}\text { Any Grade, } \\
\text { Any Course }\end{array}$ & $\begin{array}{c}\text { Advanced } \\
\text { (if Applicable) }\end{array}$ & $\begin{array}{c}\text { Basic or Intermediate } \\
\text { (if Applicable) }\end{array}$ \\
\hline English & 2 & 424 & 418 & 6 \\
Finnish & 0 & 426 & & \\
History & 264 & 162 & 206 & \\
Mathematics & 94 & 332 & & \\
Psychology & 347 & 79 & & 264 \\
Social Studies & 178 & 248 & 81 & \\
Swedish & 51 & 375 & & \\
\hline
\end{tabular}


Second, we analysed students' overall success in the Matriculation Examination and variation was found. Thus, we divided students into three groups according to their Diploma Score $(\mathrm{M}=103.95$; $\mathrm{SD}=22.61$ ) using standard deviation. Students in the low Diploma Score group had a score that was half a standard deviation below the mean (92.65) or lower. Students in the high Diploma Score group had a score that was half a standard deviation above the mean (115.26) or higher. Students in the mid Diploma Score group were in between these groups in their Diploma Score. The groups are presented in Table 3.

Table 3. Diploma Score groups.

\begin{tabular}{cccccc}
\hline & $\mathbf{n}$ & $\mathbf{M}$ & SD & Min & Max \\
\hline Low Diploma Score & 129 & 77.08 & 13.39 & 38.00 & 92.50 \\
Mid Diploma Score & 149 & 103.46 & 6.44 & 93.00 & 115.10 \\
High Diploma Score & 148 & 127.87 & 8.39 & 115.50 & 152.20 \\
\hline
\end{tabular}

\subsection{Differences in Academic Achievement between the Detected Groups}

In order to find out whether differences could be found in academic achievement at university between the detected groups, a series of MANOVAs were conducted. First, we investigated the groups based on students' subject choices. In history, there were no differences in academic achievement between the students with any grade and the students with no grade in history, Wilks' $\Lambda=1.00, F(2$, $423)=0.615, p=0.541$. In psychology, there were no differences in academic achievement between the students with any grade and the students with no grade in psychology, Wilks' $\Lambda=1.00, F(2,423)$ $=0.432, p=0.650$. In social studies, there were no differences in academic achievement between the students with any grade and no grade in social studies, Wilks' $\Lambda=0.99, \mathrm{~F}(2,423)=2.60, p=0.075$.

In mathematics, significant differences were found in academic achievement between students with any grade in the advanced course of mathematics, basic course of mathematics, and no grade in mathematics, Wilks' $\Lambda=0.95, \mathrm{~F}(4,844)=5.30, p<0.001, \eta^{2}=0.02$. Both study progress, $\mathrm{F}(2,423)=4.39$, $p=0.013, \eta^{2}=0.02$, and study success, $\mathrm{F}(2,423)=9.06, p<0.001, \eta^{2}=0.04$, showed significant effects, yet the effect sizes were small. A further Tukey post hoc test showed that students with any grade in the advanced course of mathematics progressed faster in their studies than students with no grade in mathematics $(p=0.009)$. Furthermore, students with any grade in the advanced course of mathematics were more successful in their studies than students with no grade in mathematics $(p<0.001)$ and any grade in the basic course of mathematics $(p=0.010)$. Academic achievement in the different mathematics course choice groups are presented in Table 4.

Table 4. Study progress and study success in different mathematics course choices.

\begin{tabular}{cccccc}
\hline \multirow{2}{*}{ Mathematics Course Choice } & \multicolumn{2}{c}{ Study Progress } & \multicolumn{2}{c}{ Study Success } \\
\cline { 2 - 6 } & $\mathbf{n}$ & $\mathbf{M}$ & SD & M & SD \\
\hline No grade in mathematics & 94 & 49.20 & 14.76 & 2.95 & 0.55 \\
Mathematics (basic course) & 126 & 53.10 & 14.46 & 3.04 & 0.54 \\
Mathematics (advanced course) & 206 & 54.30 & 13.10 & 3.23 & 0.59 \\
\hline
\end{tabular}

In Swedish, there were no differences in academic achievement between students with any grade in the advanced course of Swedish, intermediate course of Swedish, and or no grade in Swedish, Wilks' $\Lambda=0.99, \mathrm{~F}(4,844)=1.51, p=0.197$.

Secondly, we investigated groups that were based on students' overall performance in the Matriculation Examination, namely Diploma Score groups (Table 5). We found that students in different Diploma Score groups were different in their academic achievement, Wilk's $\Lambda=0.97, \mathrm{~F}(4$, $844)=15.01, p<0.001, \eta^{2}=0.07$. Both study progress, $\mathrm{F}(2,423)=7.34, p=0.001, \eta^{2}=0.03$, and study success, $\mathrm{F}(2,423)=30.72, p<0.001, \eta^{2}=0.13$, showed significant effects, yet the effect sizes were small 
and medium. A Dunnett's T3 post hoc test showed that students in the high Diploma Score group were progressing faster in their studies than the students in the low Diploma Score group $(p=0.002)$ and the students in the mid Diploma Score group $(p=0.039)$. Furthermore, a Tukey post hoc test showed that students in the high Diploma Score group were more successful in their studies than students in the low Diploma Score group $(p<0.001)$ and students in the mid Diploma Score group $(p<0.001)$. In addition, students in the mid Diploma Score group were more successful in their studies than the students in the low Diploma Score group $(p=0.028)$.

Table 5. Study progress and study success in different Diploma Score groups.

\begin{tabular}{cccccc}
\hline \multirow{2}{*}{ Diploma Score Group } & \multicolumn{2}{c}{ Study Progress } & \multicolumn{2}{c}{ Study Success } \\
\cline { 2 - 6 } & $\mathbf{n}$ & $\mathbf{M}$ & SD & M & SD \\
\hline Low Diploma Score & 129 & 49.72 & 15.90 & 2.88 & 0.53 \\
Mid Diploma Score & 149 & 52.32 & 10.38 & 3.05 & 0.49 \\
High Diploma Score & 148 & 56.02 & 14.79 & 3.38 & 0.59 \\
\hline
\end{tabular}

\section{Discussion}

In the present study, we found that law students' study progress and study success were related to their prior performance, particularly the overall performance in the Matriculation Examination. The findings are in line with earlier international research on associations between secondary school grades and later achievement at university [9]. Individual subjects, however, showed divergent connections, and only the grade in the advanced mathematics course was highlighted. Effect sizes in the detected findings were mostly small and this suggests that there are many factors other than prior performance that are significant in association with academic achievement.

Based on previous research findings, we assumed that we would find relationships between prior performance and study success, but not study progress. This was only partially the case. We found that the relationships were stronger between Matriculation Examination grades and study success than study progress. However, a few subjects also had significant correlations with the study progress, namely history, the mathematics advanced course, and the intermediate Swedish course. In addition, the Diploma Score, a measure for the overall performance in the Matriculation Examination, was related to both study progress and study success.

The results indicate that there was variation in students' Matriculation Examination grades and subject choices. Thus, we were able to detect different subject choice groups and different performance level groups. Comparing the groups, we found that Matriculation Examination subject choices were not related to later academic achievement, except for the advanced mathematics course. Students with a grade in this course progressed faster and were more successful than students with no grade in mathematics. Furthermore, overall performance in the Matriculation Examination distinguished students in their academic achievement. Students with strong overall performance in prior education progressed faster and were more successful in university than students with weak overall performance in prior education.

Findings on the overall performance and the advanced course of mathematics contradicted our assumption that study progress would not be related to prior performance. While earlier studies on medical students $[14,15]$ found no relationship between prior performance and study progress, there are many possible explanations for this contradiction. For instance, it has been suggested elsewhere that there might be some disciplinary differences $[19,20]$. In addition, circumstances and the overall situation of a university student have changed over the years. For instance, while a student can still determine their own study pace, there is slightly more pressure on students to progress faster in the Finnish higher education context. Furthermore, while differences between the detected groups in study progress were significant, effect sizes were small in both overall performance and mathematics. 
The influence of other cognitive, motivational, and contextual factors on study progress must not be overlooked [13].

This study supports evidence from previous research that concluded that the mathematics grade was the best predictor of academic achievement at university [12]. However, the earlier findings were concentrated on science students. While in science programmes mathematics has a vital role in learning, this is not true in the law programme. Our findings do not explain why the advanced course of mathematics seems to have importance in students' later performance in the law programme. It is not clear if students learn relevant study skills in Mathematics, or if passing the advanced test of mathematics in the Matriculation Examination requires those relevant study skills that students have acquired elsewhere. Studying in the advanced mathematics course could accustom students to hard work, as it has the heaviest workload in the upper secondary school curriculum. The routine of working hard pays off at university [7]. In addition, analytical thinking and problem-solving skills are essential in mathematics success and this might be beneficial in university studies.

\section{Limitations and Future Research Directions}

In the present study, we solely focused on law students. Extremely competitive admissions in the law programme make the group distinct from the students in less popular disciplines. The findings from the present study are thus not valid for generalising to other disciplines. In future, comparative studies between disciplines could reveal a diversity of mechanisms for academic achievement. In addition, the findings of the present study only reflect the current methods in student admissions. Students who would be admitted using new methods, e.g., Matriculation Examination-based admissions, would be a different group and the findings of this study might not be valid for them. As the reform of admissions in Finland is carried out, granting the Matriculation Examination more weight, further follow-up research is vital. While we found a surprising amount of variation in students' prior performance, the sample of the study was still selective, due to the high selectivity of the degree programme. This might lead to underestimation of the importance of the prior performance. More research is needed on larger and less selective samples. However, the practical reality in Finnish student admissions is this: high-performing students need to be differentiated based on a few grades. It is also important to note that later achievement at university can be measured only for those applicants who were actually admitted. In order to validate an admission method, the rejected applicants should be also taken into consideration. While detecting the so-called false negatives is a difficult task, potential approaches should be considered.

In the present study, we found that the law students who had taken the advanced test in mathematics in the Matriculation Examination performed stronger at university. Based on the data used in this study, we were not able to examine the reasons behind this finding. Thus, the role of mathematics skills in later learning outcomes requires more research.

Overall, the present form of the national Matriculation Examination proved to be a challenge for statistical analysis. The vast diversity of subject choices within law programme students made it difficult to define prior performance. While in other disciplines applicants may have a more homogenous selection of subjects, methods for analysing Matriculation Examination performance should be considered.

The findings of the present study provide important information for the reform of university admissions in Finland. However, in the future, more research on university admissions in the Finnish higher education context is needed. While registry data provide interesting directions, in future, it is important to include more motivational and cognitive factors in order to gain deeper understanding of the topic at hand.

Author Contributions: Supervision, H.H.; Writing - original draft, K.K. and H.H.; Writing - review \& editing, K.K. and H.H.

Funding: Open access funding provided by University of Helsinki. The first author was funded by the Ministry of Education and Culture in the National Project for Student Admissions Reform. 
Conflicts of Interest: The authors declare no conflict of interest.

\section{Appendix A}

Table A1. Planned scoring table for admissions in the Faculty of Law (http://yliopistovalinnat2020.fi).

\begin{tabular}{clllllc}
\hline LAW & L (6) & E (5) & M (4) & C (3) & B (2) & A (1) \\
\hline Finnish & 33.0 & 27.5 & 22.0 & 16.5 & 11.0 & 5.5 \\
\hline \multicolumn{7}{c}{ Applicant's four best scores } \\
\hline Biology & 22.4 & 18.6 & 14.9 & 11.2 & 7.5 & 3.7 \\
Philosophy & 20.0 & 16.7 & 13.3 & 10.0 & 6.7 & 3.3 \\
Physics & 26.5 & 22.0 & 17.6 & 13.2 & 8.8 & 4.4 \\
History & 24.5 & 20.4 & 16.3 & 12.2 & 8.2 & 4.1 \\
Chemistry & 22.4 & 18.6 & 14.9 & 11.2 & 7.5 & 3.7 \\
Language, Advanced & 28.3 & 23.6 & 18.9 & 14.1 & 9.4 & 4.7 \\
Language, Intermediate & 25.1 & 20.9 & 16.8 & 12.6 & 8.4 & 4.2 \\
Language, Basic & 22.6 & 18.9 & 15.1 & 11.3 & 7.5 & 3.8 \\
Geography & 20.0 & 16.7 & 13.3 & 10.0 & 6.7 & 3.3 \\
Mathematics, Basic & 28.3 & 23.6 & 18.9 & 14.1 & 9.4 & 4.7 \\
Mathematics, Advanced & 36.1 & 30.0 & 24.0 & 18.0 & 12.0 & 6.0 \\
Psychology & 22.4 & 18.6 & 14.9 & 11.2 & 7.5 & 3.7 \\
Health Education & 17.3 & 14.4 & 11.5 & 8.7 & 5.8 & 2.9 \\
Religion/Ethics & 24.5 & 20.4 & 16.3 & 12.2 & 8.2 & 4.1 \\
Social Studies & 20.0 & 16.7 & 13.3 & 10.0 & 6.7 & 3.3 \\
\hline
\end{tabular}

\section{References}

1. Reform of Student Admissions and Cooperation between Levels of Education. Available online: https: //minedu.fi/en/acceleration-of-transition-to-working-life (accessed on 15 August 2019).

2. Korhonen, V.; Inkinen, M.; Mattsson, M.; Toom, A. Student engagement and the transition from the first to second year in higher education. In Higher Education Transitions; Kyndt, E., Donche, V., Trigwell, K., Lindblom-Ylänne, S., Eds.; Routledge: London, UK, 2017; pp. 113-135.

3. Haarala-Muhonen, A.; Ruohoniemi, M.; Parpala, A.; Komulainen, E.; Lindblom-Ylänne, S. How do the different study profiles of first-year students predict their study success, study progress and the completion of degrees? High. Educ. 2017, 74, 949-962. [CrossRef]

4. Baik, C.; Naylor, R.; Arkoudis, S.; Dabrowski, A. Examining the experiences of first-year students with low tertiary admission scores in Australian universities. Stud. High. Educ. 2017, 44, 526-538. [CrossRef]

5. Côté, J.E.; Levine, C.G. Attitude versus aptitude: Is intelligence or motivation more important for positive higher-educational outcomes? J. Adolesc. Res. 2000, 15, 58-80. [CrossRef]

6. Donche, V.; Coertjens, L.; Van Petegem, P. Transitions to higher education: Moving beyond quantity. In Higher Education Transitions; Kyndt, E., Donche, V., Trigwell, K., Lindblom-Ylänne, S., Eds.; Routledge: London, UK, 2017; pp. 21-30.

7. Arum, R.; Roksa, J. Academically Adrift: Limited Learning on College Campuses; University of Chicago Press: Chicago, IL, USA, 2011; pp. 1-91.

8. Andersson, E. Study Success. Scand. J. Educ. Res. 2003, 47, 543-559. [CrossRef]

9. Richardson, M.; Abraham, C.; Bond, R. Psychological correlates of university students' academic performance: A systematic review and meta-analysis. Psychol. Bull. 2012, 138, 353-387. [CrossRef] [PubMed]

10. Räisänen, M.; Tuononen, T.; Postareff, L.; Hailikari, T.; Virtanen, V. Students' and Teacher's Experiences of the Validity and Reliability of Assessment in a Bioscience Course. High. Educ. Stud. 2016, 6, 181-189. [CrossRef]

11. Wagner, D.; Brahm, T. Fear of academic failure as a self-fulfilling prophecy. In Higher Education Transitions: Theory and Research; Kyndt, E., Donche, V., Trigwell, K., Lindblom-Ylänne, S., Eds.; Routledge: London, UK, 2017; pp. 13-30. 
12. Koster, A.; Verhoeven, N. Study success in science bachelor programmes: Predictive value of secondary school grades. In Higher Education Transitions; Kyndt, E., Donche, V., Trigwell, K., Lindblom-Ylänne, S., Eds.; Routledge: London, UK, 2017; pp. 84-102.

13. Hailikari, T.; Tuononen, T.; Parpala, A. Students' experiences of the factors affecting their study progress: Differences in study profiles. J. Furth. High. Educ. 2018, 42, 1-12. [CrossRef]

14. Lindblom-Ylänne, S.; Lonka, K.; Leskinen, E. Selecting students for medical school: What predicts success during basic science studies? A cognitive approach. High. Educ. 1996, 31, 507-527. [CrossRef]

15. Lindblom-Ylänne, S.; Lonka, K.; Leskinen, E. On the predictive value of entry-level skills for successful studying in medical school. High. Educ. 1999, 37, 239-258. [CrossRef]

16. Kallio, E.; Utriainen, J.; Niilo-Rämä, M.; Räikkönen, E. Lukiomenestyksen ja yliopisto-opintojen aloitushetken iän yhteys yliopisto-opinnoissa menestymiseen ja opintojen etenemiseen: Seurantatutkimus. Kasvatus 2018, 49, 287-296.

17. Diseth, Å. Self-efficacy, goal orientations and learning strategies as mediators between preceding and subsequent academic achievement. Learn. Individ. Differ. 2011, 21, 191-195. [CrossRef]

18. Cliffordson, C.; Askling, B. Different grounds for admission: Its effects on recruitment and achievement in medical education. Scand. J. Educ. Res. 2006, 50, 45-62. [CrossRef]

19. Kupiainen, S.; Marjanen, J.; Ouakrim-Soivio, N. Ylioppilas Valintojen Pyörteissä. Lukio-Opinnot, Ylioppilastutkinto ja Korkeakoulujen Opiskelijavalinta; Suomen Ainedidaktinen Tutkimusseura: Helsinki, Finland, 2018.

20. Häkkinen, I. Do University Entrance Exams Predict Academic Achievement? Working Paper No. 2004: 16; Department of Economics, Uppsala University: Uppsala, Sweden, 2004; pp. 2-38.

21. Lonka, K.; Ahola, K. Activating instruction: How to foster study and thinking skills in higher education. Eur. J. Psychol. Educ. 1995, 10, 351-368. [CrossRef]

22. O'Hare, L.; McGuinness, C. The validity of critical thinking tests for predicting degree performance: A longitudinal study. Int. J. Educ. Res. 2015, 72, 162-172. [CrossRef]

23. Applicants and Selected Candidates. Available online: https://vipunen.fi/en-gb/university/Pages/Hakeneetja-hyv\%C3\%A4ksytyt.aspx (accessed on 15 August 2019).

24. Hyytinen, H.; Haarala-Muhonen, A.; Räisänen, M. How do self-regulation and self-efficacy beliefs associate with law students' experiences of teaching and learning? Uniped 2019, 42, 74-90. [CrossRef]

25. Lindblom-Ylänne, S.; Parpala, A.; Postareff, L. Challenges in analysing change in students' approaches to learning. In Learning Patterns in Higher Education; Gijbels, D., Donche, V., Richardson, J., Vermunt, J., Eds.; Routledge: New York, NY, USA, 2013; pp. 232-248.

26. Hyytinen, H.; Nissinen, K.; Ursin, J.; Toom, A.; Lindblom-Ylänne, S. Problematising the equivalence of the test results of performance-based critical thinking tests for undergraduate students. Stud. Educ. Eval. 2015, 44, 1-8. [CrossRef]

(C) 2019 by the authors. Licensee MDPI, Basel, Switzerland. This article is an open access article distributed under the terms and conditions of the Creative Commons Attribution (CC BY) license (http://creativecommons.org/licenses/by/4.0/). 